\title{
ABO blood group system and occurrence of ischemic stroke
}

\author{
Sistema $A B O$ de grupos sanguíneos e ocorrência de acidente vascular cerebral isquêmico \\ Rafaella Chiodini LOTZ1', Carolina da Silveira WELTER', Silvia Aparecida RAMOS ${ }^{1}$, Leslie Ecker FERREIRA ${ }^{1,2}$, \\ Norberto Luiz CABRAL ${ }^{1,2,3 *}$, Paulo Henrique Condeixa de FRANÇA ${ }^{1,2}$
}

\begin{abstract}
Background: Ischemic stroke (IS) is a multifactorial disease that presents high rates of morbimortality in Brazil. Several studies proved that there is a link between the ABO blood group system and the occurrence of thrombotic events. Nonetheless, its association with IS is not well established. Objective: For that reason, the purpose hereof was to investigate the relation between the ABO blood groups and the occurrence of IS in a Brazilian cohort of cerebrovascular diseases. Methods: Five hundred and twenty-nine subjects were included over 12 months, from which 275 presented an IS episode and 254 composed the control group. Blood samples were drawn for direct and reverse serotyping. The control and IS groups were compared regarding the traditional risk factors and the distribution of the ABO blood groups. Results: The IS group presented a higher prevalence of systemic arterial hypertension (SAH), diabetes mellitus, smoking habits, family history, cardiopathy, and sedentary lifestyle in comparison with the control group. The AB blood type prevailed among the patients (5.1 vs. $1.6 \% ; p<0.05)$ and this group had more SAH cases in comparison with the 0 type group (92.9 vs. $67.3 \%$; $p<0.05)$. Conclusions: Our results suggest that the occurrence of IS is more frequent among patients of the AB blood type.
\end{abstract}

Keywords: Ischemic Stroke; ABO Blood-Group System; Risk Factors.

\section{RESUMO}

Antecedentes: $\mathrm{O}$ acidente vascular cerebral isquêmico (AVCI) é uma doença multifatorial que apresenta altas taxas de morbimortalidade no Brasil. Vários estudos provaram que existe uma ligação entre o sistema ABO de grupos sanguíneos e a ocorrência de eventos trombóticos. No entanto, sua associação com AVCI não está bem estabelecida. Objetivo: Por essa razão, o objetivo deste trabalho foi investigar a relação entre os grupos sanguíneos ABO e a ocorrência de AVCl em uma coorte brasileira de doenças cerebrovasculares. Métodos: Ao longo de 12 meses foram incluídos 529 indivíduos, dos quais 275 apresentaram um episódio de AVCl e 254 compuseram o grupo controle. Amostras de sangue foram coletadas para sorotipagem direta e reversa. Os grupos controle e AVCI foram comparados em relação aos fatores de risco tradicionais e à distribuição dos grupos sanguíneos ABO. Resultados: 0 grupo AVCl apresentou maior prevalência de hipertensão arterial sistêmica (HAS), diabetes mellitus, tabagismo, história familiar, cardiopatia e estilo de vida sedentário em comparação ao grupo controle. 0 tipo sanguíneo AB prevaleceu entre os pacientes $(5,1$ vs. 1,6\%; $p<0,05)$ e apresentou mais casos de HAS em comparação ao tipo O (92,9 vs. 67,3\%; $p<0,05)$. Conclusões: Nossos resultados sugerem que a ocorrência de AVCl é mais frequente entre os pacientes do tipo sanguíneo $A B$.

Palavras-chave: AVC Isquêmico; Sistema ABO de Grupos Sanguíneos; Fatores de Risco.

\footnotetext{
'Universidade da Região de Joinville, Departamento de Medicina, Joinville SC, Brazil.

${ }^{2}$ Universidade da Região de Joinville, Joinville Stroke Biobank, Joinville SC, Brazil.

${ }^{3}$ Hospital Municipal São José, Serviço de Neurologia, Joinville SC, Brazil.

*In memoriam

RCL (D) https://orcid.org/0000-0003-0886-2281; CSW (D) https://orcid.org/0000-0002-4864-9605; SAR (D) https://orcid.org/0000-0003-2393-7819; LEF (iD https://orcid.org/0000-0003-0276-9043; NLC (D) https://orcid.org/0000-0001-5829-9699; PHCF (D) https://orcid.org/0000-0002-1750-9132 Support: This work was supported by the Research Support Fund from the Universidade da Região de Joinville (INVITATION LETTER No 02/16 - Call for Projects Linked to Stricto Sensu Programs).

Correspondence: Paulo Henrique Condeixa de França; Email: ph.franca@univille.br

Conflicts of interest: There is no conflict of interest to declare.

Authors' contributions: RCL, CSW: conceived and designed the research, acquired the data, analyzed and interpreted the data and drafted the manuscript; SAR: conceived and designed the research, handled supervision, analyzed and interpreted the data; LEF, NLC: analyzed and interpreted the data and made critical revision of the manuscript for important intellectual content; PHCF: conceived and designed the research, handled supervision, analyzed and interpreted the data and made critical revision of the manuscript for important intellectual content.
}

Received on June 03, 2020; Received in its final form on November 17, 2020; Accepted on January 11, 2021. 


\section{INTRODUCTION}

Stroke is a common pathological condition caused by changes in blood flow to the brain. It is responsible for high morbidity and mortality rates, resulting in at least 5 million deaths and more than 15 million non-fatal cases per year. It can be ischemic- or hemorrhagic in origin. Hemorrhagic cases are due to rupture of a cerebral blood vessel, whereas ischemic cases are due to obstruction of a vessel by thrombosis or embolism ${ }^{1,2,3}$.

Ischemic stroke (IS) is the most frequent type in Brazil ${ }^{4}$. It is considered a complex disorder caused by a combination of influences of several genes and environmental factors ${ }^{5}$. The risk factors related to the disease can be divided into modifiable and non-modifiable ${ }^{6}$. Non-modifiable factors include age, gender, ethnicity and heredity. On the other hand, modifiable factors include systemic arterial hypertension (SAH), smoking habits, atrial fibrillation (AF), dyslipidemias, sedentary lifestyle, and heart disease ${ }^{7}$.

The ABO system is considered the most important blood group system. It is well established that blood type interferes with the hemostasis because it affects factor VIII and the Von Willebrand factor $(\mathrm{VWF})^{8}$. Subjects of blood group $\mathrm{O}$ have lower levels of VWF and factor VIII than subjects of non-O blood groups (A, B, and AB). Approximately $70 \%$ of the variation in the plasmatic levels of the VWF and VIII factors is determined by genetics, with $30 \%$ of the genetic variation attributable to the subject's blood type. Remarkably, VWF levels are $25 \%$ higher in subjects of the non-O blood group?.

Besides the relation of the $\mathrm{ABO}$ system with blood transfusions compatibility, studies link this system with cardiovascular diseases. The association between non-O blood groups and the risk of developing venous thromboembolism (VTE) is well established ${ }^{10}$. Spiezia et al. reported in their case control study that subjects of the non-O blood groups had a 2.2 times higher risk of developing VTE than O-group subjects. Nevertheless, the link with arterial thrombotic events, such as myocardial infarction and IS was not well established ${ }^{11}$.

Sabino et al. investigated the frequency of ABO blood group polymorphisms and its association with IS and peripheral arterial diseases. The resulting data suggest a role of the non-O blood type in the pathogenesis of thrombotic events and a probable protective effect of the O blood type regarding the occurrence of $\mathrm{IS}^{12}$. Williams et al. inferred that the variants of the $A B O$ gene are associated with cardioembolic stroke and large vessel stroke, but not with small vessels stroke $^{13}$. In China, preliminary results from a case control study support the evidence that single nucleotide polymorphisms in the $A B O$ gene may contribute to susceptibility to atherothrombotic IS, without a significant association with lacunar IS ${ }^{14}$. Additionally, Zakai et al. inferred that the AB blood type was linked to an increased ICVA risk, and $60 \%$ of such association was mediated by the levels of factor VIII ${ }^{8}$.
In this sense, the purpose hereof was to investigate the association between the $\mathrm{ABO}$ blood type and the occurrence of IS in the JOINVASC cohort.

\section{METHODS}

This case control study was originated from the JOINVASC cohort - Population-based Epidemiological Study in Cerebrovascular Diseases in Joinville. During one year, patients that had an IS episode and control subjects (people that never had a stroke episode, also residents of the city of Joinville, Santa Catarina, Brazil), whose age was equal or above 18 years, were included in the study. To classify the IS subtypes, we employed the TOAST (Trial of Org 10172 in Acute Stroke Treatment) diagnosis criteria. Five categories were described: (1) atherosclerosis of large arteries or atherothrombotic; (2) cardioembolic; (3) lacunar; (4) other etiologies; and (5) indeterminate etiology ${ }^{15}$. We collected data on traditional risk factors and compared prevalence levels between the control group and IS group, based on data routinely collected by the JOINVASC cohort ${ }^{16}$. After finding a higher frequency of certain blood types in patients, these individuals were distributed according to traditional risk factors and ischemic stroke subtypes considering the most frequent blood type vs. all other types and vs. O type (some authors indicate a possible protective effect for the incidence of thrombotic events ${ }^{12}$ ).

Blood samples from the patients and control subjects were collected by peripheral venous puncture for blood typing. We used the Anti-A, Anti-B, and Anti-AB (Fresenius Kabi, Barueri, Brazil) Soroclone ${ }^{\circledast}$ kit, according to the manufacturer's instructions. Briefly, a drop of each antiserum and a drop $(50 \mu \mathrm{L})$ of recently prepared $5 \%$ red cell suspension were mixed inside tubes. After homogenization and centrifugation, the presence or absence of agglutination was used to characterize the occurrence of reaction. As a complement, the reverse $\mathrm{ABO}$ classification was used to determine serum antibodies using the REVERCEL PLUS ${ }^{\circledast}$ (Fresenius Kabi) reagent.

In addition to descriptive statistical analysis, means and standard deviations were calculated for quantitative variables and relative frequencies for the qualitative variables. The chi-square test was used to compare proportions and the Student's $t$-test for verification of significant differences between means. The significance level established was $p<0.05$.

The study was approved by the Research Ethics Committee of the Universidade da Região de Joinville (protocol 45305615.5.0000.5366; ruling 1.138.314).

\section{RESULTS}

During the 12 months of the study, we registered 275 cases of IS (128 women and 147 men) and 254 subjects composed the control group (171 women and 83 men) (Table 1). 
Table 1. Prevalence of risk factors in the ischemic stroke group and control group.

\begin{tabular}{|c|c|c|c|}
\hline & IS $(n=275)$ & Control $(n=254)$ & $\mathrm{p}$-value \\
\hline Age (years) & & & $<0.01^{\#}$ \\
\hline Mean $\pm S D$ & $65.7 \pm 13.9$ & $57.4 \pm 13.0$ & \\
\hline Range & $22-98$ & $20-99$ & \\
\hline Gender [n (\%)] & & & $<0.01 *$ \\
\hline Female & $128(46.5)$ & $171(67.3)$ & \\
\hline Male & $147(53.6)$ & $83(32.7)$ & \\
\hline Skin color $[\mathrm{n}(\%)]$ & & & $0.042^{\star, a}$ \\
\hline White & $254(92.4)$ & $245(96.5)$ & \\
\hline Non-white & $21(7.6)$ & $9(3.5)$ & \\
\hline SAH [n (\%)] & $197(71.6)$ & $111(43.7)$ & $<0.01^{\star}$ \\
\hline $\mathrm{DM}[\mathrm{n}(\%)]$ & $81(29.4)$ & $40(15.7)$ & $<0.01 *$ \\
\hline Smoking habits [n (\%)] & $158(57.4)$ & $82(32.3)$ & $<0.01^{*, b}$ \\
\hline Alcoholism [n (\%)] & $77(28.0)$ & $65(25.6)$ & $0.53^{*, c}$ \\
\hline Family history [n (\%)] & $78(28.4)$ & $5(2.0)$ & $<0.01 *$ \\
\hline Dyslipidemia [n (\%)] & $64(23.3)$ & $70(27.5)$ & $0.32 *$ \\
\hline Cardiopathy [n (\%)] & $85(30.9)$ & $32(12.6)$ & $<0.01 *$ \\
\hline Lifestyle [n (\%)] & & & $<0.01^{\star, d}$ \\
\hline Active & $61(22.2)$ & $110(43.3)$ & \\
\hline Inactive & $214(77.8)$ & $144(56.7)$ & \\
\hline \multicolumn{4}{|l|}{ Blood group [n (\%)] } \\
\hline A & $125(45.1)$ & $99(39)$ & $0.132^{\star}$ \\
\hline B & $23(8.4)$ & $31(12.2)$ & $0.145^{\star}$ \\
\hline$A B$ & $14(5.1)$ & $4(1.6)$ & $0.026^{*}$ \\
\hline 0 & $113(41.1)$ & $120(47.2)$ & $0.154^{\star}$ \\
\hline
\end{tabular}

IS: ischemic stroke; SD: standard deviation; SAH: systemic arterial hypertension; DM: diabetes mellitus; \#Student's t-test; *chi-square test ( ${ }^{\text {awhite }}$ vs. non-white; 'smoking and former smoking vs. non-smoking; 'yes, eventual/social and moderate/heavy vs. non-alcoholic; 'active vs. inactive).

The mean age of the IS group (65.7 \pm 13.9 years) was higher than the control group ( $57.7 \pm 12.9$ years; $\mathrm{p}<0.01)$. The male gender was more represented among the patients (53.6 vs. $32.7 \%$; $\mathrm{p}<0.01$ ) (Table 1). Regarding the IS subtypes, according to the TOAST criteria, $30.5 \%$ of the cases were of lacunar etiology, followed by $29.8 \%$ of indeterminate etiology, $16 \%$ of cardioembolic cause, $16.4 \%$ of atherothrombotic IS, and a minority of other causes (6.5\%).

The SAH was the most frequent risk factor for IS, being present in $71.6 \%$ of the patients and in $43.7 \%$ of the control subjects $(\mathrm{p}<0.01)$ (Table 1). The IS group also had a higher prevalence of diabetes mellitus (DM; 29.4 vs. 15.7\%; $\mathrm{p}<0.01$ ), smoking habits ( 57.4 vs. $32.3 \%$; $\mathrm{p}<0.01$ ), family history ( 28.4 vs. $2 \%$; $\mathrm{p}<0.05$ ), cardiopathy (30.9 vs. $12.6 \%$; $\mathrm{p}<0.05)$, and sedentary lifestyle ( 77.8 vs. $56.7 \%$; $p<0.05$ ). Table 1 also shows the distribution and comparison of the prevalence rates between cases and controls according to the $\mathrm{ABO}$ system. The AB blood type was more prevalent among patients ( $5.1 \mathrm{vs.} 1.6 \%$; $\mathrm{p}<0.05$ ).

Table 2 shows the distribution of blood types according to the IS-related risk factors investigated. People with AB blood type had a higher prevalence of SAH compared with people with O type ( 92.9 vs. $67.3 \%$; $p<0.005$ ). There was no significant difference between blood groups for the other risk factors studied.

\section{DISCUSSION}

Our results suggest that the occurrence of IS is more frequent among patients of the $\mathrm{AB}$ blood type. On the other hand, the occurrence of SAH seems to be more significant among these patients.

Several authors have compared the distribution of IS occurrence among ABO system blood groups. Blood donors in Denmark and Sweden were followed for diagnosis of thromboembolism and arterial events between 1987 and 2012. Compared to blood group O, non-O blood groups were associated with higher incidence of both venous and arterial thromboembolic events. Among arterial events, incidence rate ratios (IRRs) were generally low, but still significantly increased, with IRRs of 1.10 (95\%CI 1.05-1.14) for 
Table 2. Risk factors and ischemic stroke (IS) subtype according to the ABO system blood type.

\begin{tabular}{|c|c|c|c|c|c|}
\hline & & $A B(n=14)$ & $0(n=113)$ & NON-AB $(n=261)$ & $p$-value \\
\hline \multirow{2}{*}{ Age } & Mean $\pm S D$ & $64.9 \pm 15.1$ & $66.7 \pm 12.5$ & $65.7 \pm 13.9$ & $0.623^{\alpha}$ \\
\hline & Range & $30-84$ & $29-98$ & $22-95$ & $0.822^{\beta}$ \\
\hline \multirow{2}{*}{ Gender [n (\%)] } & Female & $8(57.1)$ & $51(45.1)$ & $120(46.0)$ & $0.395^{\alpha}$ \\
\hline & Male & $6(42.9)$ & $62(54.9)$ & $141(54.0)$ & $0.415^{\beta}$ \\
\hline SAH [n (\%)] & & $13(92.9)$ & 76 (67.3) & $184(70.5)$ & $\begin{array}{l}0.048^{\alpha} \\
0.071^{\beta}\end{array}$ \\
\hline $\mathrm{DM}[\mathrm{n}(\%)]$ & & $3(21.4)$ & $34(30.0)$ & $78(29.9)$ & $\begin{array}{l}0.501^{\alpha} \\
0.499^{\beta}\end{array}$ \\
\hline Smoking habits [n (\%)] & & $6(42.8)$ & $71(62.8)$ & $152(58.2)$ & $\begin{array}{l}0.149^{\alpha, \alpha} \\
0.257^{\beta, \alpha}\end{array}$ \\
\hline Alcoholism [n (\%)] & & $2(14.3)$ & $36(31.8)$ & $75(28.7)$ & $\begin{array}{l}0.176^{\alpha, \beta} \\
0.241^{\beta, \beta}\end{array}$ \\
\hline Family history [n (\%)] & & $3(21.4)$ & $35(31.0)$ & $75(28.7)$ & $\begin{array}{l}0.462^{\alpha} \\
0.555^{\beta}\end{array}$ \\
\hline Dyslipidemia [n (\%)] & & $2(14.3)$ & $26(10.0)$ & $63(24.1)$ & $\begin{array}{l}0.543^{\alpha} \\
0.440^{\beta}\end{array}$ \\
\hline Cardiopathy [n (\%)] & & $4(28.6)$ & $38(33.6)$ & $83(31.8)$ & $\begin{array}{l}0.704^{\alpha} \\
0.800^{\beta}\end{array}$ \\
\hline \multirow{2}{*}{ Lifestyle [n (\%)] } & Active & $1(7.1)$ & $27(23.9)$ & $58(22.2)$ & $0.154^{\alpha, c}$ \\
\hline & Inactive & $13(92.9)$ & $86(76.1)$ & $203(77.8)$ & $0.181^{\beta, c}$ \\
\hline \multirow{5}{*}{ TOAST [n (\%)] } & Atherothrombotic & $2(14.3)$ & $22(19.5)$ & $43(16.5)$ & - \\
\hline & Cardioembolic & $2(14.3)$ & $20(17.7)$ & $44(16.8)$ & - \\
\hline & Lacunar & $5(35.7)$ & $37(32.7)$ & $79(30.3)$ & - \\
\hline & Others & $1(7.1)$ & $4(3.6)$ & $17(6.5)$ & - \\
\hline & Indeterminate & $4(28.6)$ & $30(26.5)$ & 78 (29.9) & - \\
\hline
\end{tabular}

SD: standard deviation; SAH: systemic arterial hypertension; \#Student's $t$-test; ${ }^{*}$ chi-square test (asmoking and former smoking vs. non-smoking; byes, eventual/ social and moderate/heavy vs. non-alcoholic; ${ }^{\circ}$ active vs. inactive); ${ }^{\circledR A B}$ vs. O; ${ }^{\beta} \mathrm{AB}$ vs. non-AB; TOAST: Trial of Org 10172 in Acute Stroke Treatment.

myocardial infarction and 1.07 (95\%CI 1.02-1.12) for stroke in non-O blood groups individuals compared to blood group $\mathrm{O}^{17}$. Zakai et al., in their REGARDS study to access the racial and regional differences on stroke and with 30,239 participants of the USA between the years of 2003 and 2007, reported a hazard ratio (HR) of 1.18 for the $\mathrm{AB}$ group for the occurrence of stroke in comparison with the $\mathrm{O}$ group. The authors also evaluated factor VIII in plasma by an immunoenzymatic test and they reported a higher level in the $\mathrm{AB}$ group subjects and estimated that factor VIII mediated $60 \%$ of the association between the $\mathrm{AB}$ group and stroke risk $^{8}$. To our knowledge, this was the only study to date that reported an association between the AB blood type and IS. Such link was expected based on the studies that reported a higher occurrence of thrombotic events in subjects of the non-O blood groups.

Sabino et al., evaluating polymorphisms of the ABO system blood groups and the association with IS risk and peripheral artery disease, found data suggesting a possible protective factor of the $\mathrm{O}$ group in the pathogenesis of thrombotic events $^{12}$. In another study assessing the association between venous thromboembolism and blood types, Sode et al. found the $\mathrm{ABO}$ system responsible for $20 \%$ of the risk attributable to venous thromboembolism ${ }^{10}$. In this same study, which comprised 2,279 events of venous thromboembolism, the HR of 1.4 (95\%CI 1.3-1.5) was found for venous thromboembolism in subjects of the non-O groups in comparison with the O-group subjects ${ }^{10}$. The EUROCLOT study was designed in three stages to identify common variations that affect the fibrin structure and function in the normal population and significant single nucleotide polymorphisms linked to the occurrence of stroke. The authors reported that non-O blood groups were associated to a higher risk of peripheral vascular disease, heart attacks, and IS ${ }^{13}$. Consequently, although the link between the $\mathrm{ABO}$ system with thrombotic events is well established in the literature, further studies are still required with more diverse populations to confirm the association between the $\mathrm{AB}$ blood group and the occurrence of IS.

As expected, in our study, a higher prevalence of SAH was found among the patients with IS than in control subjects. The association between IS and hypertension is well 
established, and $\mathrm{SAH}$ is considered the most important modifiable risk factor for IS. The meta-analysis "Prospective Studies Collaborations" of 61 studies and a million participants found a strong link between blood pressure and mortality rate by IS by age. This study presented a log-linear increase of the mortality rate by IS according to age for increases of 20 and $10 \mathrm{mmHg}$ in the systolic and diastolic pressures, respectively ${ }^{18}$. The same association was found by Rapsomanik et al. in their cohort that electronically gathered the data of 1.25 million patients without cardiovascular diseases at first and with a minimal age of 30 years, resulting in HR of 1.35 (95\%CI 1.28-1.42) for the occurrence of IS with an increase of $20 \mathrm{mmHg}$ in the systolic pressure ${ }^{19}$.

In addition to hypertension, we also found a higher prevalence of DM, cardiopathy, sedentary lifestyle, smoking habits, and positive family history among patients in comparison with the control subjects. We know that some heart diseases can increase the risk of IS, from which AF is considered the most important and treatable pre-IS cardiopathy ${ }^{20}$. The Framingham study associated non-valvular AF with a three- to five-time higher risk of IS. Additionally, the IS risk decreased with age for all other cardiovascular conditions, except for AF. In subjects aged 80 to 89 years, AF was the only cardiovascular condition that independently affected IS risk $^{20}$. The higher prevalence of DM among patients was also expected, since diabetic subjects are more susceptible to atherosclerosis and have a higher frequency of atherogenic risk factors. The relationship between DM and IS was also reported in the Framingham study, in which glucose-intolerant subjects had twice the risk of cerebral infarction than non-diabetic subjects ${ }^{20}$. As for the modifiable risk factors such as smoking habits and sedentary lifestyle, studies have reported their association with IS risk. Regarding smoking habits, both the Framingham study and the Nurses Health study - a cohort that collected 12 years of data from 117,006 female nurses aged 30 to 55 years in 11 of the most populous states in the USA - reported a reduction in IS risk with smoking cessation $^{20,21}$. Therefore, all differences found between patients and control subjects in modifiable and non-modifiable risk factors related to IS were already expected and support the association of our results with well-established findings in the literature ${ }^{3,22,23}$.

Our results suggest a higher prevalence of $\mathrm{SAH}$ in the $\mathrm{AB}$ group subjects in comparison with the O-group subjects. We found no other study supporting the link between hypertension and the $\mathrm{ABO}$ system's blood groups. Additionally, there was no evidence of an association between blood groups and any of the other risk factors investigated. However, Zakai et al. reported a relationship with diabetes, with higher prevalence in the $\mathrm{AB}$ group than in the $\mathrm{O}$ group ${ }^{8}$. However, this association was not found in our study.

Our main finding - AB blood group patients had a higher frequency of IS - could be affected by the small number of subjects with this blood type, which is the first limitation of the study, followed by the fact that it was conducted in a single center. However, we know that the prevalence of the $\mathrm{AB}$ blood group in the Brazilian population is actually low. Studies conducted in different regions of the country with blood donors identified prevalences that ranged from 3.13 to $4 \%^{24,25}$. In addition, because of the limited number of individuals in the patient and control groups, as well as the lack of homogeneity of baseline characteristics between groups, it is not possible to perform inferenceseg, by multiple logistic regression, about the $\mathrm{AB}$ blood group being a risk factor for the ischemic event. To overcome these limitations and confirm the results presented here, we recommend increasing the number of evaluated subjects and replicating the study in other centers. In addition, the clinical utility of ABO system for IS prediction warrants further study, since the determination of blood group phenotypes is easy and robust and there is no influence of acute phase response on blood group assessment.

\section{ACKNOWLEDGMENTS}

We thank the staff of JOINVASC cohort at the Hospital Municipal São José in Joinville and the technical support of Joinville Stroke Biobank at UNIVILLE.

\section{References}

1. Giles MF, Rothwell PM. Measuring the prevalence of stroke. Neuroepidemiology. 2008 Jun;30(4):205-6. https://doi. org/10.1159/000126913

2. Person TA, Blair SN, Daniels SR, Eckel RH, Fair JM Fortmann SP, Franklin BA, et al. AHA Guidelines for Primary Prevention of Cardiovascular disease and Stroke: 2002 Update: Consensus Panel Guide to Comprehensive Risk Reduction for Adult Patients Without Coronary or Other Atherosclerotic Vascular Diseases. American Heart Association Science Advisory and Coordinating Committee. Circulation. 2002 Jul;106(3):388-91. https://doi.org/10.1161/01. CIR.0000020190.45892.75
3. Cabral NL, Longo AL, Moro CH, Amaral CH, Kiss HC. Epidemiology of cerebrovascular disease in Joinville, Brazil. An institutional study. Arq Neuro-Psiquiatr. 1997 Sep;55(3A):357-63. https://doi.org/10.1590/ s0004-282x1997000300002

4. Minelli C, Fen LF, Minelli DPC. Stroke incidence prognosis, 30-day and a 1-year case fatality rates in Matão, Brazil: a population-based prospective study. Stroke. 2007 Nov;38(11):2906-11. https://doi. org/10.1161/STROKEAHA.107.484139

5. Cheng YC, Cole JW, Mitchell BD, Kittner SJ. Genetics of ischemic stroke in young adults. Circ Cardiovasc Genet. 2014 Jun;7(3):383-92. https://doi.org/10.1161/CIRCGENETICS.113.000390 
6. Romero JR, Morris J, Pikula A. Stroke prevention: modifying risk factors. Ther Adv Cardiovasc Dis. 2008 Aug;2(4):287-303. https://doi. org/10.1177/1753944708093847

7. Bhatt VR, Mainali NR, Sigdel S, Aryal M, Hamal N, Khanal S, et al. Risk factors of stroke. N Engl J Med. 2006 Apr;354(16):1706-17. https:// doi.org/10.1056/NEJMoa060989

8. Zakai NA, Judd SE, Alexander K, McClure LA, Kissela BM, Howard $G$, et al. ABO blood type and stroke risk: The reasons for geographic and racial differences in stroke study. J Thromb Haemost. 2014 Apr;12(4):564-70. https://doi.org/10.1111/jth.12507

9. Franchini M, Makris M. Non-O blood group: an important genetic risk factor for venous thromboembolism. Blood Transfus. 2013 Apr;11(2):164-5. https://doi.org/10.2450/2012.0087-12

10. Sode BF, Allin KH, Dahl M, Gyntelberg F, Nordestgaard BG. Risk of venous thromboembolism and myocardial infarction associated with factor $V$ Leiden and prothrombin mutations and blood type. CMAJ. 2013 Mar;185(5):E229-37. https://doi.org/10.1503/ cmaj.121636

11. Spiezia L, Campello E, Bon M, Tison T, Milan M, Simioni P, et al. ABO blood groups and the risk of venous thrombosis in patients with inherited thrombophilia. Blood Transfus. 2013 Apr;11(2):250-3. https://doi.org/10.2450/2012.0060-12

12. Sabino A, Ribeiro DD, Domingheti CP, Rios DR, Dusse LM, Carvalho $\mathrm{MD}$, et al. ABO blood group polymorphisms and risk for ischemic stroke and peripheral arterial disease. Mol Biol Rep. 2014 Mar;41(3):1771-7. https://doi.org/10.1007/s11033-014-3026-8

13. Williams FM, Carter AM, Hysi PG, Surdulescu G, Hodgkiss D, Soranzo $\mathrm{N}$, et al. Ischemic Stroke Is Associated with the ABO Locus: The EuroCLOT Study. Ann Neurol. 2013 Jan;73(1):16-31. https://doi. org/10.1002/ana.23838

14. Ling X, Zheng Y, Tao J, Zheng Z, Chen L. Association study of polymorphisms in the $\mathrm{ABO}$ gene with ischemic stroke in the Chinese population. BMC Neurol. 2016;16(1):146. https://doi.org/10.1002/ jcla.22329

15. Adams Jr HP, Bendixen BH, Kappelle LJ, Biller J, Love BB, Gordon DL, et al. Classification of subtype of acute ischemic stroke. Definitions for use in a multicenter clinical trial. TOAST. Trial of Org 10172 in Acute Stroke Treatment. Stroke. 1993 Jan;24(1):35-41. https://doi. org/10.1161/01.str.24.1.35

16. Cabral NL, Cougo-Pinto PT, Magalhaes PS, Longo AL, Moro CH, Amaral CH, et al. Trends of stroke incidence from 1995 to 2013 in
Joinville, Brazil. Neuroepidemiology. 2016 May;46(4):273-81. https:// doi.org/10.1159/000445060

17. Vasan SK, Rostgaard K, Majeed A, Ullum H, Titlestad KE, Pedersen $\mathrm{OB}$, et al. ABO blood group and risk of thromboembolic and arterial disease: a study of 1.5 million blood donors. Circulation. 2016 Apr;133(15):1449-57; discussion 1457. https://doi.org/10.1161/ CIRCULATIONAHA.115.017563

18. Prospective Studies Collaboration, Lewington S, Whitlock G, Clarke $\mathrm{R}$, Sherliker P, Emberson J, et al. Blood cholesterol and vascular mortality by age, sex and blood pressure: a meta-analysis of individual data from 61 prospective studies with 55,000 vascular deaths. Lancet. 2007 Dec;370(9602):1829-39. https://doi. org/10.1016/S0140-6736(07)61778-4

19. Rapsomaniki E, Timmis A, George J, Pujades-Todriguez M, Shah AD, Denaxas S, et al. Blood pressure and incidence of twelve cardiovascular diseases: lifetime risks, healthy life-years lost, and age-specific associations in 1.25 million people. Lancet. 2014 May;383(9932):1899911. https://doi.org/10.1016/S0140-6736(14)60685-1

20. Wolf PA, Benjamin EJ, Belanger AJ, Kannel WB, Levy D, D’Agostino RB. Secular trends in the prevalence of atrial fibrillation: the Framingham Study Am Heart J. 1996 Apr;131(4):790-5. https://doi. org/10.1016/s0002-8703(96)90288-4

21. Colditz GA. The Nurses' Health Study: findings during 10 years of follow up of a cohort of U.S. women. Curr Prob Obstet Gynecol Fertil. 1990;45(11):774-5.

22. Wolf PA, D’Agostino RB, Kannel WB, Bonita R, Belanger AJ. Cigarette smoking as a risk factor for stroke: the Framingham Study. JAMA. 1988 Feb;259(7):1025-9. https://doi.org/10.1001/ jama.1988.03720070025028

23. Kawachi I, Colditz GA, Stampfer MJ, Willett WC, Manson JE, Rosner B, et al. Smoking cessation and decreased risk of stroke in women. JAMA. 1993 Jan;269(2):232-6. https://doi.org/10.1001/ jama.1993.03500020066033

24. Novaretti M, Dorlhiac-Llacer P, Chamone D. Estudo de grupos sanguíneos em doadores de sangue caucasoides e negroides na cidade de São Paulo. Rev Bras Hematol Hemoter. 2000 Apr;22(1):2332. https://doi.org/10.1590/S1516-84842000000100004

25. Coelho E, Diniz R, Reis J, Gomes K. Frequência de grupos sanguíneos dos sistemas ABO e Rh na população de Belo Horizonte - MG. Rev Bras Anal Clin. 2010; 42(4): 245-7. https://doi.org/10.34117/ bjdv6n10-324 